\title{
THE INTERACTION OF THE INVESTIGATOR, THE HEAD OF THE INVESTIGATIVE BODY AND THE PROSECUTOR IN THE INITIATION AND IMPLEMENTATION OF CRIMINAL PROSECUTION
}

\author{
Valentina A. Lazareva \\ Samara National Research University named after Academician S.P. Korolev, Samara, Russian Federation
}

Introduction: criminal prosecution is a specific legal concept that means a certain type of law enforcement activity. Having introduced this concept into legal use, the Criminal Procedure Code of the Russian Federation pointed to the purpose of this activity - the exposure of a suspect accused of committing a crime (Paragraph 56 of Article 5), its compliance with the scheduling criminal proceedings (Part 2 of Article 6), types (Chapter 3) and subjects (Chapter 6). The content of this activity, the methods of its implementation indicate that the criminal prosecution coincides with the procedural activities of the inquirer, investigator and prosecutor, that is, it is carried out through the performance of each of the named persons of their powers. This allows us to put forward and substantiate the thesis that a preliminary investigation is a criminal prosecution carried out in the procedural form of a proceeding or inquiry, that is, an activity aimed at identifying and exposing a person, a suspect, or an accused of committing a crime, whose efficiency depends on a properly organized procedural interaction of the entities carrying out this activity, which together form the prosecutorial power of the state. The purpose of the study: to identify the reasons for the lack of effective cooperation of the criminal prosecution authorities and suggest the ways to eliminate them. The objectives of the study: to characterize the role (function) of the bodies, inquiry, investigation, prosecutor's office in pre-trial proceedings in a criminal case, to formulate and base the conclusion that pre-trial proceedings in a criminal case are a form of criminal prosecution as a common type of criminal procedural activity for the inquirer, investigator and prosecutor. The dialectical, logical, systematic, structural-functional and other general scientific research methods were used in the preparation of the paper; as well as the comparative-legal, formal-legal and other specific scientific methods. Results: the paper shows that the reform of the preliminary investigation bodies, which resulted in the removal of investigators from administrative subordination to the prosecutor, the redistribution of powers between the prosecutor and the head of the investigative body in favor of the latter, did not lead to the expected increase in the procedural independence and independence of the investigator, but had a negative impact on the level of legality of pre-trial proceedings. The amendments made to the Criminal Procedure Code of the Russian Federation in 2007 and later proved to be insufficiently thought out; they are not logical and do not conform well with other norms of criminal procedure law. The shortcomings of the legal regulation of the procedure for exercising the powers of the head of the investigative body and the prosecutor, their interaction with the investigator and among themselves, were only partially corrected by Law No. 404-F of December 28, 2010. Conclusions: the need to improve the efficiency of interaction of the investigator with the head of the investigative body and the prosecutor requires a serious revision of a number of norms of the Criminal Procedure Code of the Russian Federation.

Key words: preliminary investigation, prosecutor, evidence, investigative actions, criminal prosecution, prosecution authority.

Citation. Lazareva V.A. The Interaction of the Investigator, the Head of the Investigative Body and the Prosecutor in the Initiation and Implementation of Criminal Prosecution. Legal Concept = Pravovaya paradigma, 2021, vol. 20, no. 2, pp. 41-48. (in Russian). DOI: https://doi.org/10.15688/lc.jvolsu.2021.2.6 


\title{
ВЗАИМОДЕЙСТВИЕ СЛЕДОВАТЕЛЯ, РУКОВОДИТЕЛЯ СЛЕДСТВЕННОГО ОРГАНА И ПРОКУРОРА ПРИ ВОЗБУЖДЕНИИ И ОСУЩЕСТВЛЕНИИ УГОЛОВНОГО ПРЕСЛЕДОВАНИЯ
}

\author{
Валентина Александровна Лазарева \\ Самарский национальный исследовательский университет им. академика С.П. Королева, \\ г. Самара, Российская Федерация
}

\begin{abstract}
Введение: уголовное преследование - специфическое юридическое понятие, означающее определенный вид правоохранительной деятельности. Введя это понятие в юридический обиход, УПК РФ указал на цель этой деятельности - изобличение подозреваемого, обвиняемого в совершении преступления (п. 56 ст. 5), ее соответствие назначению уголовного судопроизводства (ч. 2 ст. 6), виды (гл. 3) и субъекты (гл. 6). Содержание этой деятельности, способы ее осуществления указывают на то, что уголовное преследование совпадает с процессуальной деятельностью дознавателя, следователя и прокурора, то есть она осуществляется посредством выполнения каждым из названных лиц принадлежащих им полномочий. Сказанное позволяет выдвинуть и обосновать тезис о том, что предварительное расследование есть осуществляемое в процессуальной форме следствия или дознания уголовное преследование, то есть деятельность по выявлению и изобличению лица, подозреваемого, обвиняемого в совершении преступления, эффективность которой зависит от правильно организованного процессуального взаимодействия осуществляющих эту деятельность субъектов, образующих в своей совокупности обвинительную власть государства. Цель исследования: выявить причины недостаточно эффективного взаимодействия органов уголовного преследования и предложить способы их устранения. Задачи исследования: охарактеризовать роль (функцию) органов дознания, следствия, прокуратуры в досудебном производстве по уголовному делу, сформулировать и обосновать вывод о том, что досудебное производство по уголовному делу представляет собой форму уголовного преследования как общего для дознавателя, следователя и прокурора вида уголовно-процессуальной деятельности. При подготовке статьи использованы диалектический, логический, системный, структурно-функциональный и другие общенаучные методы исследования, а также сравнительно-правовой, формальноюридический и другие частно-научные методы. Результаты: в статье показано, что реформа органов предварительного следствия, выразившаяся в выведении следователей из-под административного подчинения прокурору, перераспределении полномочий между прокурором и руководителем следственного органа в пользу последнего, не привела к ожидаемому повышению процессуальной самостоятельности и независимости следователя, но отрицательно сказалась на уровне законности досудебного производства. Изменения, внесенные в УПК РФ в 2007 г. и позднее, оказались недостаточно продуманными, они не логичны и плохо согласуются с другими нормами уголовно-процессуального права. Недостатки правового регулирования порядка осуществления полномочий руководителя следственного органа и прокурора, взаимодействия их со следователем и между собой законом № 404-Ф от 28 декабря 2010 г. были исправлены лишь частично. Выводы: необходимость повышения эффективности взаимодействия следователя, руководителя следственного органа и прокурора требует серьезного пересмотра ряда норм Уголовно-процессуального кодекса РФ.

Ключевые слова: предварительное расследование, прокурор, доказывание, следственные действия, уголовное преследование, обвинительная власть.
\end{abstract}

Цитирование. Лазарева В. А. Взаимодействие следователя, руководителя следственного органа и прокурора при возбуждении и осуществлении уголовного преследования // Legal Concept $=$ Правовая парадигма. -2021. - T. 20, № 2. - C. 41-48. - DOI: https://doi.org/10.15688/lc.jvolsu.2021.2.6

\section{Введение}

Уголовное преследование - специфическое юридическое понятие, характеризующее определенный вид правоохранительной деятельности. Введя данное понятие в юридичес- кий обиход, Уголовно-процессуальный кодекс РФ (2001) указал на цель этой деятельности изобличение подозреваемого, обвиняемого в совершении преступления (п. 56 ст. 5), ее соответствие назначению уголовного судопроизводства (ч. 2 ст. 6), виды (гл. 3) и субъекты 
(гл. 6). Но каково содержание этой деятельности, каковы способы ее осуществления? Прямого ответа на вопрос закон не дает, однако вышеназванные нормы не оставляют сомнений - уголовное преследование, олицетворяя осуществляемую каждым из них процессуальную функцию, в целом совпадает с процессуальной деятельностью дознавателя, следователя и прокурора, а значит осуществляется посредством выполнения каждым из них принадлежащих им процессуальных полномочий. Сказанное позволяет рассматривать предварительное расследование как осуществляемое в процессуальной форме (следствия или дознания) уголовное преследование, то есть деятельность по изобличению лица, подозреваемого, обвиняемого в совершении преступления [4, с. 22], несмотря на остающееся в науке стремление сохранить представление о предварительном расследовании исключительно как познавательной деятельности, направленной на полное, всестороннее и объективное выяснение (исследование) обстоятельств совершенного преступления в целях установления истины [6, с. 111 и сл.].

Закрепленное законом единство процессуальной функции дознавателя, следователя, прокурора не равнозначно одинаковости форм и способов деятельности, но требует общего подхода к оценке ее качества и результатов. В силу сквозного характера этой функции эффективность работы одного выполняющего ее субъекта влияет на эффективность деятельности другого и уголовного судопроизводства в целом. Отсюда важное значение приобретает не только организационное взаимодействие органов дознания, следствия и прокурора, обеспечиваемое в том числе средствами, лежащими за пределами уголовно-процессуального регулирования, но и одинаковое понимание субъектами уголовно-процессуальной деятельности сущности законодательных предписаний, зависящее от их четкости, ясности, логичности и последовательности.

\section{Проблемы взаимодействия субъектов уголовного преследования}

Название гл. 6 УПК РФ «Участники уголовного судопроизводства со стороны обвинения» однозначно указывает, что орган доз- нания, начальник органа дознания, руководитель подразделения дознания, дознаватель, следователь, руководитель следственного органа и прокурор выполняют в уголовном процессе функцию выдвижения и обоснования утверждения о совершении определенным лицом преступления, то есть осуществляют доказывание. Такой вывод с очевидностью вытекает и из содержания ст. 14 Уголовнопроцессуального кодекса РФ, возлагающей бремя доказывания обвинения на субъектов, осуществляющих одноименную функцию. Таким образом, несмотря на разность решаемых перечисленными субъектами задач и предоставленных им для этого полномочий, общее направление их деятельности подчинено одной цели, а значит успех общей деятельности слагается из того, насколько эффективно работает каждое звено этой системы и насколько слажено они взаимодействуют. Сказанное означает, что органы и должностные лица, наделенные правом и облеченные обязанностью осуществлять уголовное преследование, представляют собой отдельную ветвь государственной власти - обвинительную власть, функционирование которой в уголовном процессе мы обосновали в ранее опубликованных работах [3]. Ограниченная рамками уголовного судопроизводства обвинительная власть обеспечивает реализацию его назначения - привлечение лица, совершившего преступление, к законной (уголовной) ответственности (ст. 6 УПК РФ).

Взаимодействие субъектов обвинительной власти основано на принципе различения форм осуществления общей функции: одни субъекты осуществляют поиск и собирание доказательств, подтверждающих виновность изобличаемого лица, другие выполняют контроль и руководство их работой, задача прокурора - обеспечить законность досудебного производства. Действуя в пределах своих полномочий, каждый субъект вносит свой вклад в достижение общей цели.

Взаимодействие субъектов обвинительной власти в ходе уголовно-процессуальной деятельности регулируется законом, что, однако, не исключает возможности возникновения коллизий и конфликтов, некоторые из которых имеют принципиальный характер. Наиболее принципиальным является вопрос о 
иерархии субъектов обвинительной власти; на его рассмотрении и остановимся.

Единственный субъект публичного уголовного преследования, участвующий в уголовно-процессуальной деятельности на всех ее этапах - от принятия сообщения о преступлении до исполнения приговора, - прокурор. Полномочия прокурора по надзору за процессуальной деятельностью органов следствия и дознания, его право оценивать (принимать или отвергать) результаты деятельности органов предварительного расследования, прерогатива принятия решения о передаче уголовного дела на рассмотрение суда, исключительность права продолжить уголовное преследование в суде дают прокурору власть над органами предварительного расследования и над сформулированным ими обвинением, то есть ставят прокурора во главу обвинительной власти.

Возглавляя обвинительную власть, прокурор несет полную ответственность за эффективность и законность уголовного преследования на всех этапах уголовного судопроизводства и полное право распоряжаться обвинением - продолжать или прекращать уголовное преследование, вносить в содержание обвинения определенные изменения, отказаться от использования в целях уголовного преследования недопустимых доказательств. Деятельность прокурора на любой стадии уголовного процесса обеспечивает возможность дальнейшего движения дела, задает направление этого движения, при этом она во многом зависит от эффективности работы всей системы органов уголовного преследования, поэтому прокурор должен иметь возможность влиять на процессуальную деятельность этой системы. В решении вопросов взаимодействия субъектов уголовного преследования законодатель не может руководствоваться ничем, кроме задачи изобличения виновного.

Непонимание этого обстоятельства, как представляется, и привело к сумятице в законодательном регулировании полномочий прокурора в досудебном производстве по уголовному делу, начавшейся в 2007 г. в связи с реорганизацией органов предварительного следствия, завершившейся выведением следователей, входящих в структуру органов прокуратуры, из-под административного подчине- ния прокурору и созданием самостоятельного следственного комитета РФ. Считалось, что таким путем можно повысить как процессуальную самостоятельность следователя и, соответственно, качество самого расследования, так и уровень прокурорского надзора, освобожденного от забот по руководству следствием. В связи с этим возникла необходимость разделения и разграничений полномочий по руководству предварительным следствием и надзору за соблюдением в ходе следствия закона. Законом от 5 июня 2007 № 87-Ф3 власть прокурора над осуществлением уголовного преследования была подорвана, поскольку значительная часть его полномочий передана руководителю следственного органа (так стал называться теперь бывший начальник следственного отдела), влияние которого на предварительное следствие в связи с этим значительно возросло. Не останавливаясь на этом подробно, поскольку развернувшаяся в то время научная дискуссия хорошо известна и описана [6, с. 92-111], а возникшие в практике проблемы недостаточно продуманного правового регулирования частично были преодолены последующими изменениями уголовно-процессуального закона (Ф3 № 404 от 27 декабря 2010 г.), назовем лишь наиболее важные, не решенные до настоящего времени, но нуждающиеся в решении вопросы.

Один из существенных вопросов касается лишения прокурора права начать уголовное преследование, то есть возбудить уголовное дело. Ответ на этот вопрос для нас очевиден. Возбуждение уголовного дела о совершенном преступлении, а значит и уголовного преследования совершившего это преступление лица, - объективно обусловленная и необходимая реакция прокурора, как органа надзора за законностью в стране, на выявленное им в процессе осуществления надзорных полномочий нарушение Уголовного кодекса. Возбудить уголовное дело и потребовать его расследования для прокурора так же естественно, как принести протест или представление на нарушение закона или применить другую меру прокурорского реагирования. Чем руководствовался законодатель, лишив прокурора этого права, можно только догадываться, но последствия этого непродуманного реше- 
ния стали очевидны буквально сразу. В 2010 г. постановление прокурора о направлении материалов в орган предварительного расследования для решения вопроса о возбуждении уголовного дела было включено в перечень поводов к возбуждению уголовного дела, что, возможно, и повысило статус этого постановления, но не является решением проблемы, так как не препятствует следователю отказать в возбуждении уголовного дела, хотя бы и с согласия руководителя следственного органа, неоднократно. Такое решение разрушает нормальное взаимодействие органа надзора с поднадзорным ему органом, фактически оно означает, что для следователя постановление прокурора, содержащее требование о возбуждении уголовного преследования, не обязательно. В ситуации выявления следователем факта отсутствия оснований для возбуждения уголовного дела даже в условиях действующего правового регулирования правильнее было бы сообщить об этом прокурору и направить ему материалы проведенной проверки для принятия процессуального решения. В 2008 г. законодатель предоставил право возбуждения уголовного дела руководителю следственного органа, к которому уже перешли другие полномочия, ранее осуществляемые прокурором. В итоге мы получили ситуацию, когда незаконное или необоснованное постановление следователя (руководителя следственного органа) об отказе в возбуждении уголовного дела мог отменить руководитель (соответственно вышестоящий руководитель следственного органа), но не мог прокурор, которому поднадзорен в том числе и тот самый руководитель. При этом руководитель следственного органа, в отличие от прокурора, имел право, отменив постановление следователя, возбудить уголовное дело. Прокурору же право отменить постановление об отказе в возбуждении уголовного дела было возвращено только в 2010 г., а правом возбудить уголовное дело, даже при отмене соответствующего постановления не только следователя, но и дознавателя, он все еще не обладает. Такое законодательное решение и не логично, и не эффективно, о чем хорошо известно как в теории, так и на практике. Добавим к этому, что при производстве предварительного расследования в форме дознания процессуальное руководство и надзор не разделены, здесь прокурор сохранил все ранее принадлежавшие ему полномочия. При таких обстоятельствах отказ в возможности возбудить уголовное дело, подследственное органу дознания, необъясним вообще.

Отдельного внимания заслуживает вопрос об отмене необоснованного постановления о возбуждении уголовного дела. На первый взгляд, этот вопрос в ч. 4 ст. 146 УПК РФ решен, и решен логично - отменить такое постановление прокурор вправе в течение 24 часов с момента получения материалов, послуживших основанием для возбуждения уголовного дела. Указанное право прокурора обеспечивается обязанностью лица, возбудившего уголовное дело, незамедлительно направить ему копию соответствующего постановления, то есть сразу по его подписании. При этом, однако, срок представления прокурору материалов, послуживших основанием для возбуждения уголовного дела, как и обязанность их представления, законом не регламентируются, что ставит под сомнение реализацию указания на незамедлительность отмены незаконного постановления о возбуждении уголовного дела, с которым связано начало уголовного преследования, применение мер процессуального принуждения, производство следственных действий, ограничивающих права и свободы личности и т. д. Если фактически расследование уже осуществляется, единственно законной возможностью исправить допущенную ошибку может быть только решение о прекращении уголовного дела, поэтому в одной из своих прежних публикаций, обратив на это внимание, мы когда-то предложили дополнить перечень оснований прекращения дела незаконностью (необоснованностью) его возбуждения [2], но, к сожалению, не были услышаны законодателем.

Странным и совершенно непонятным образом в ст. 146 УПК РФ даже не упоминается о том, что правом отменить постановление следователя о возбуждении уголовного дела обладает не только прокурор, но и руководитель следственного органа, хотя наличие такого права предусмотрено ст. 39 (п. 2 ч. 1) УПК, при этом срок принятия им такого решения в этой норме не указан. Значит ли это, что отмена руководителем следственного 
органа постановления о возбуждении уголовного дела возможна в любой момент производства предварительного расследования? На одно из последствий такого необдуманного решения указывает, в частности, С. Никифоров: отмена постановления о возбуждении уголовного дела руководителем следственного органа используется «для улучшения ведомственных показателей, связанных с сокращением числа прекращенных уголовных дел» [5, c. 40]. Надо ли понимать это так, что число незаконно возбужденных дел не влияет на показатели следственной работы? Вопрос, понятное дело, риторический.

Добавим к этому принципиальную, на наш взгляд, недопустимость применения ч. 4 ст. 39 УПК РФ к постановлениям о возбуждении уголовного дела. Напомним, что несогласие (письменное возражение) следователя с требованием прокурора об отмене незаконного или необоснованного постановления рассматривается руководителем следственного органа в течение 5 суток, который в случае несогласия с требованием выносит мотивированное постановление и еще в течение 5 суток направляет его прокурору, а тот в соответствии с ч. 6 ст. 39 УПК обращается к вышестоящему прокурору и т. д. Пока ведомства спорят, что происходит с уголовным делом, с лицом, в отношении которого оно возбуждено?

Справедливости ради, необходимо отметить, что процедура возбуждения уголовного дела, и сама по себе достаточно проблематичная, за 20 лет действия УПК РФ много раз подвергалась разного рода изменениям в поисках оптимального решения, в том числе с позиций перераспределения процессуальных ролей. Например, в первоначальной редакции УПК в качестве гарантии законности и обоснованности постановления о возбуждении уголовного дела предусматривалось предварительное согласие прокурора. Оказавшееся неэффективным и даже неисполнимым [1, с. 95], это положение вскоре было отменено, хотя и нынешнее решение, с учетом изложенного выше, не представляется окончательным. Такое метание законодателя между диаметрально противоположными решениями, одно из которых исходит из недопустимости начала уголовного преследования без одобрения прокурора, а второе не допускает прокурора к этому решению, свидетельствует об отсутствии ясной концепции развития уголовного процесса в целом.

Еще одна проблема - обеспеченность возможности влияния прокурора на законность уголовного преследования. Кажется ясным, что право (оно же и обязанность) осуществлять надзор за производством предварительного следствия, в том числе требовать устранения нарушений закона, отменять постановление нижестоящего прокурора, рассматривать несогласие руководителя следственного органа с требованиями прокурора и т. д., не может быть реализовано, если орган надзора лишен доступа к материалам дела. Этого полномочия прокурор сначала - в 2007 г. - был лишен, потом законом № 226-Ф3 от 2 декабря 2008 г. в ст. 37 включена ч. 2.1, которая «разрешила» прокурору ознакомление с материалами дела, находящегося в производстве, «по мотивированному письменному запросу». Иначе как мелким желанием угодить руководству Следственного комитета такое решение объяснить трудно. При этом как-то никто не обратил внимания на то, что это правило по недосмотру было распространено и на дела, расследование которых осуществляется в форме дознания, но вопрос о праве прокурора знакомиться с материалами находящегося в производстве дела возник исключительно в отношении органов следствия.

Хаотичность вносимых в УПК изменений отразилась на корявости законодательной техники, затрудняющей восприятие некоторых положений закона, которые противоречат элементарным правилам русского языка. Читаем, к примеру, п. 5.1 ч. 2 ст. 37: «истребовать и проверять законность решений следователя или руководителя следственного органа об отказе в возбуждении уголовного дела, приостановлении или прекращении уголовного дела». Что истребовать-то? Если решения, то в этом нет необходимости, поскольку следователь обязан соответствующими нормами направить прокурору копии всех принимаемых им постановлений, и зачем дополнительно указывать на право проверять их законность? В теории это дополнение было воспринято как восстановление права требовать от следователя для ознакомления уголовное дело безо всякой мотивировки [6, c. 102], однако процитированный пункт закона 
оснований для такого оптимизма не дает. Кроме того, право прокурора истребовать для проверки уголовное дело не может быть ограничено необходимостью проверки законности только названных в этом пункте постановлений. Прокурор рассматривает жалобы участников уголовного процесса на нарушение их прав и интересов в процессе принятия или при отказе в принятии и других решений о непризнании потерпевшим, гражданским истцом, отказе в удовлетворении ходатайства, продлении срока следствия, при производстве следственных действий, применении мер пресечения. Он должен иметь возможность о3накомиться с материалами дела, готовясь к процедуре рассмотрения судом ходатайств в порядке ст. 108, 109, 165 УПК и др., при рассмотрении жалоб в порядке ст. 125 УПК и вообще везде, где от него требуется обоснованная позиция. Ограничение права прокурора на ознакомление с материалами уголовного дела равносильно лишению возможности осуществлять надзор за соблюдением закона при производстве предварительного следствия, точно также как лишение такого права руководителя следственного органа ограничивает его возможность осуществлять процессуальное руководство следствием.

Остановимся еще на одной проблеме. С момента подписания следователем и руководителем следственного органа обвинительного заключения их власть над обвинением заканчивается. В качестве аргумента достаточно указать на то, что в это время заканчивается и срок предварительного расследования. Переход всей полноты обвинительной власти к прокурору означает, что он получает право и возможность распоряжаться обвинением по своему усмотрению - передавать дело на рассмотрение суда, прекращать уголовное преследование, менять объем обвинения и его уголовно-правовую квалификацию. Власть прокурора над уголовным делом ограничена только законом и правилом о недопустимости поворота к худшему - если для такого поворота есть основания, прокурор возвращает уголовное дело для производства дополнительного расследования. Сказанное подтверждается и правом прокурора отказаться от обвинения и изменить его с соблюдением правила о недопустимости поворота к худшему как на стадии назначения судебного заседания, так и при рассмотрении уголовного дела по существу или при любой форме пересмотра приговора. На этом фоне странно выглядит отсутствие такой возможности при рассмотрении уголовного дела, поступившего с обвинительным заключением, у прокурора, который по статусу выше своего помощника, которому он поручит поддерживать государственное обвинение. Получается, что прокурор, усмотрев основания для принятия такого решения, должен сначала утвердить обвинительное заключение, а потом уже подписать заявление об отказе от обвинения, которое, как известно, влечет прекращение дела, или о его изменении, что можно рассматривать как частичный отказ от обвинения. Странная, однако, логика, при которой прокурор ставится в зависимость от позиции поднадзорного ему органа следствия. Между тем даже незначительный намек на ослабление надзора за законностью предварительного следствия таит в себе значительную опасность.

Изложенным проблема взаимодействия следователя, руководителя следственного органа и прокурора, разумеется, не исчерпывается. Наша задача - привлечь внимание законодателя к необходимости тщательнее продумывать вносимые в УПК изменения, руководствуясь при этом не только интересами отдельных правоприменителей, но и научнообоснованными рекомендациями.

\section{Выводы}

Эффективное выполнение органами следствия и прокуратуры общей для них функции уголовного преследования (реализация обвинительной власти) нуждается в более системном, чем сегодня, правовом регулировании с учетом решаемых каждым из них задач. Необходимо четко определить пределы власти, реализуемой следователем и руководителем следственного органа, с одной стороны, и прокурора - с другой, с этих позиций пересмотреть изменения, внесенные в УПК РФ в 2007-2010 годах.

\section{СПИСОК ЛИТЕРАТУРЫ}

1. Актуальные проблемы возбуждения уголовного дела : учеб. пособие / В. Н. Григорьев, 


\section{ГЛАВНАЯ ТЕМА НОМЕРА}

А. В. Новиков, Е. А. Прохорова, Д. Н. Слабкая. М. : Моск. ун-т МВД России им. В. Я. Кикотя, 2016. $107 \mathrm{c}$.

2. Лазарева, В. А. Долгожданные изменения в статусе прокурора (закон от 28 декабря 2010 г. № 404-Ф3) / В. А. Лазарева // Уголовное судопроизводство. - 2011. - № 3. - С. 2-6.

3. Лазарева, В. А. Обвинительная власть / В. А. Лазарева // Уголовное судопроизводство. 2012. - № 1. - C. 14-18.

4. Лазарева, В. А. Прокурор в уголовном процессе / В. А. Лазарева. - М. : Юрайт, 2011.-296 с.

5. Никифоров, С. Отмена постановления о возбуждении уголовного дела / С. Никифоров // Законность. -2011 . - № 1. - С. 40-42.

6. Шейфер, С. А. Досудебное производство в России: этапы развития следственной, судебной и прокурорской власти / С. А. Шейфер. - М. : Норма : Инфра-М, 2019. - 192 с.

\section{REFERENCES}

1. Grigoriev V.N., Novikov A.V., Prokhorova E.A., Slabkaya D.N. Aktualnyye problemy vozbuzhdeniya ugolovnogo dela: ucheb. posobiye [Actual Problems of Initiating a Criminal Case. Textbook]. Moscow, Mosk. un-t MVD Rossii im. V.Ya. Kikotya, 2016. 107 p.

2. Lazareva V.A. Dolgozhdannyye izmeneniya v statuse prokurora (zakon ot 28 dekabrya $2010 \mathrm{~g}$. № 404-FZ) [Long-Awaited Changes in the Status of the Prosecutor (Law of December 28, 2010 No. 404-FZ)]. Ugolovnoye sudoproizvodstvo [Criminal Proceedings], 2011, no. 3, pp. 2-6.

3. Lazareva V.A. Obvinitelnaya vlast [Accusatory Power]. Ugolovnoye sudoproizvodstvo [Criminal Proceedings], 2012, no. 1, pp. 14-18.

4. Lazareva V.A. Prokuror v ugolovnom protsesse [Prosecutor in Criminal Proceedings]. Moscow, Yurayt Publ., 2011.296 p.

5. Nikiforov S. Otmena postanovleniya o vozbuzhdenii ugolovnogo dela [Cancellation of the Resolution on the Initiation of a Criminal Case]. Zakonnost [The Rule of Law], 2011, no. 1, pp. 40-42.

6. Shafer S.A. Dosudebnoye proizvodstvo $v$ Rossii: etapy razvitiya sledstvennoy, sudebnoy $i$ prokurorskoy vlasti [Pre-Trial Proceedings in Russia: Stages of Development of the Investigative, Judicial and Prosecutorial Authorities]. Moscow, Norma Publ.; Infra-M Publ., 2019. 192 p.

\section{Information About the Author}

Valentina A. Lazareva, Doctor of Sciences (Jurisprudence), Professor, Department of Criminal Procedure and Criminalistics, Samara National Research University named after Academician S.P. Korolev, Akademika Pavlova St, 1, 443011 Samara, Russian Federation, v.a.lazareva@mail.ru, https://orcid.org/0000-0003-2725-9517

\section{Информация об авторе}

Валентина Александровна Лазарева, доктор юридических наук, профессор, профессор кафедры уголовного процесса и криминалистики Юридического института, Самарский национальный исследовательский университет им. академика С.П. Королева, ул. Академика Павлова, 1, 443011 г. Самара, Российская Федерация, v.a.lazareva@mail.ru, https://orcid.org/0000-0003-2725-9517 